ing that hypnotics in a large number of persons are calculated to give rise to a craving for their continued use.

\title{
Bibliography and References.
}

'Tuke's Diet of Psychological Medicine- "Sedatives."

Latham and English's Systematic Trealment-"Insomnia and Mental Disease."

Hale White, Materia Medica.

Encyclopedia Medica, vol. v-" Hypnotics."

Craig's Psychological Medicine.

(1) Sir George Savage.-" Sleep and Sleeplessness, Brit. Med. Journ., November 8th, 1913 .

(2) Dr. Robert Jones.- "Pain and Sleeplessness," The Lancet, September 6th, 1913 .

(3) Encyclopadia Medica, "Hæmatoporphyrinuria."

(4) Stoddart's Mind and its Disorders.

(5) Dr. W. B. Willcox.- " Veronal Poisoning," The Lancet, October 26th, 1913 ; also "A Fatal Case of Veronal Poisoning," Brit. Med. Tourn., April 18th, 1914.

(6) Brit Med. Journ., 1913 , I, p. 566.

(7) J. M. H. Munro, "Veronal Poisoning," Brit. Med. Journ., April I8th, 1914 .

(8) Dr. W. B. Willcox, "The Use and Abuse of Hypnotics," Brit. Med. Journ., September $13^{\text {th, }} 1913$

(9) Martindale and Westcott, "Extra Pharmacopœia."

(I0) Public Health Bulletin No. 56, Washington Government Printing Office, 1912.

The Relationship between Epilepsy and Tuberculosis. By B. Henry Shaw, M.B., Senior Assistant Medical Officer, County Mental Hospital, Stafford.

IN their report on this Asylum for I913, the Lunacy Commissioners state: "Almost 20 per cent. of the patients in each of the Staffordshire asylums are epileptics; this unusually high proportion appears to obtain in each of the Staffordshire asylums, and to be a subject worthy of further inquiry locally." It is also noteworthy that associated with this high proportion of epileptics is a high tuberculosis death-rate, viz., $25^{\circ} 2$ per cent., the average epileptic percentage of the number of patients remaining at the year's end in county and borough asylums in England and Wales being, for I9II, 12.5, while the proportion of tuber- 
cular deaths per cent. of deaths from all causes (I902-IgII) is I6.6.

In the Commissioners' report (1913) on Wittingham Asylum, Lancashire, they state: "We notice that the percentage of epileptic patients in the Asylum at the beginning of the year was only $9^{\circ} 2$-as compared with $12 \cdot 8$, the average in asylumsand to-day it was about the same. From what we know of the epileptic insane in the Lancashire workhouses, we fear that these figures cannot be taken as any evidence of the immunity of the county from this disease." In view of the fact mentioned, and also that other insane persons are retained in workhouses, it was considered advisable to ascertain these numbers so that they could be correlated with those in this Asylum, and I have to thank the clerks to the various local unions for kindly supplying me with such information.

Leaving out the unions of Lichfield and Cannock, as the majority of their cases go to Burntwood Asylum, and dividing the remaining unions into industrial (comprising the unions of Wolverhampton, Dudley, and Stourbridge) and rural areas (comprising those of Newport, Uttoxeter, Stone, Seisdon, and Stafford), the following table shows the number of male and female epileptic and non-epileptic insane persons in the asylum and workhouses and the population of such areas:

\begin{tabular}{|c|c|c|c|c|c|c|c|c|}
\hline & \multicolumn{4}{|c|}{ In Asylum. } & \multicolumn{4}{|c|}{$\begin{array}{l}\text { Total both in Asylum and } \\
\text { workhouses. }\end{array}$} \\
\hline & \multicolumn{2}{|c|}{ Non-epileptic. } & \multicolumn{2}{|c|}{ Epileptic. } & \multicolumn{2}{|c|}{ Non-epileptic. } & \multicolumn{2}{|c|}{ Epileptic. } \\
\hline & M. & F. & м. & F. & M. & F. & M. & F. \\
\hline $\begin{array}{l}\text { Rural areas, population } \\
\text { 108,433. } \\
\text { Industrial areas, population } \\
308,466 \text {. }\end{array}$ & $\begin{array}{r}96 \\
309\end{array}$ & $\begin{array}{r}98 \\
279\end{array}$ & $\begin{array}{r}15 \\
57\end{array}$ & 77 & $\begin{array}{c}108 \\
3^{87}\end{array}$ & $\begin{array}{l}109 \\
370\end{array}$ & $\begin{array}{r}18 \\
108\end{array}$ & $\begin{array}{r}16 \\
132\end{array}$ \\
\hline
\end{tabular}

Taking the percentage of epileptics on the total number resident of each sex belonging to the different areas, we get the following :

\begin{tabular}{|c|c|c|c|c|c|}
\hline & & \multicolumn{2}{|c|}{ Asylum. } & \multicolumn{2}{|c|}{ Asslum and workhouse. } \\
\hline & & M. & F. & M. & F. \\
\hline $\begin{array}{l}\text { Rural areas } \\
\text { Industrial areas }\end{array}$ & 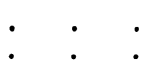 & $\begin{array}{l}13.5 \\
154\end{array}$ & $\begin{array}{l}12 \cdot 5 \\
21 \cdot 6\end{array}$ & $\begin{array}{l}14 \cdot 3 \\
21 \cdot 8\end{array}$ & $\begin{array}{l}12 \cdot 8 \\
26 \cdot 2\end{array}$ \\
\hline
\end{tabular}


These figures, which were compiled in mid-summer, I9r3, show that at that time the percentage in the Asylum of epileptic patients from these unions was $20^{\circ} 8$, whereas the average for England and Wales, as pointed out by the Commissioners, is 12.8. It will be seen from the above analysis that our excessive ratio is due to the industrial districts, and that urbanisation tells, as far as epilepsy is concerned, more on the female population than on the male, the returns from the rural areas showing a smaller proportion of female than male epileptics. Dr. Hamblin Smith very kindly informs me that since he took over duty as Medical Officer of Stafford Prison in September, IgIr, the total number of prisoners admitted have been : males, 5313; females, 965; of these, 13 males and 2 females were epileptic, and of 165 cases reported as feeble-minded, 2.4 per cent. were epileptics. $\mathrm{He}$ is of opinion also that the number of epileptics admitted to Stafford Prison is markedly less than obtains in other prisons where he has been medical officer; whether this signifies that the mental reduction associated with epilepsy is greater in degree in this neighbourhood than elsewhere, or whether the insanity associated with epilepsy is more readily recognised, one can only conjecture.

The following table shows the proportion of deaths per 1000 living at subjoined ages in Staffordshire (urban and rural aggregates) and Wolverhampton :

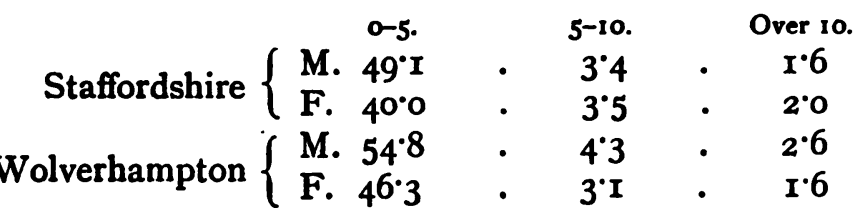

from which it is apparent that in Wolverhampton at the ages when epilepsy becomes established there is a relatively greater male death-rate than obtains for females, as compared with the county totals. This difference is really greater than appears, as the Wolverhampton figures are included in the averages for Staffordshire, but the fact that more females relatively to males survive in Wolverhampton at the ages when epilepsy develops is significant, also the fact that tuberculosis universally in early childhood is more fatal amongst boys than girls, the total figures for England and Wales being respectively 4,805 and 4,072 under the age of five. These facts go far to explain our excessive

L.X. 
female epileptic ratios, bearing in mind the relationship between epilepsy and tuberculosis to be referred to later.

In order to help in throwing some light on the cause of our excessive epileptic incidence, I have reviewed the histories of I5 I epileptic females admitted to this Institution during the past ten years, r904-1913, all of which came directly under my observation. During this period there were in all $\mathrm{I}, \mathrm{I} / 44$ female patients admitted, of which number there were from the industrial and rural areas above-mentioned 756 and $35 \mathrm{I}$ respectively, the corresponding number of epileptics being II4 and 30-giving a proportion of 8.54 per cent. of epileptics on the total number admitted from the rural area, the corresponding urban figures being $15 \circ 8$. Taking the total number of epileptics admitted during this period (Ig04-I913) the percentage on the total admissions is 12.8 . The corresponding percentage for England and Wales for the period I907-rgrr is given in the Commissioners' Report as 6.6. My colleague Dr. Bennett, has very kindly examined the male admission records here for the same period (1904-1913), and informs me that the percentage of male epileptics to total number admitted works out at $\mathrm{II}^{*} 4$, the corresponding average for England and Wales being 9*2. These figures afford, therefore, further proof of our special indebtedness in this district to the female sex for our excessive epileptic population, the male epileptic admission rate for the ten years $1904-1913$ being $2: 2$ per cent. above the average, while the female rate is 6.2 above-practically double the average. As to the causation of this I will have more to say later, but the following table gives the etiological factors ascertained in the ${ }_{5} \mathrm{I}$ epileptic female admissions, together with certain associated states :

Insane heredity : Paternal . . . . . I2 Maternal . . . . . I4 Brothers and sisters . . . I2 Uncles and aunts, but unknown whether paternal or maternal

Alcoholic : Paternal • $. \quad . \quad . \quad . \quad . \quad 3$

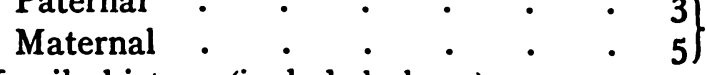

Epileptic family history (included above) . . 7

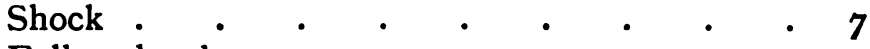

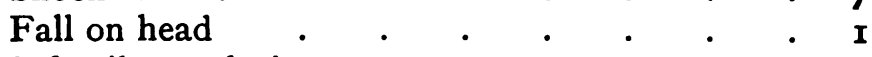
Infantile paralysis $\quad \cdot \quad \cdot \quad \cdot \quad \cdot \quad \cdot \quad \cdot 4$ 
Personal history of alcohol . . . . . . I5

Mitral regurgitation .

Aortic

showing hereditary nervous instability in one form or another in $33^{\circ} 7$ per cent. It is hardly necessary to point out that this figure does not represent a true index-many persons are only able to speak about their parents, and know nothing whatever of uncles and aunts, and many are unwilling to admit hereditary defect of this nature. The after history of the 1,174 patients as far as this Institution is concerned is given in the following table :

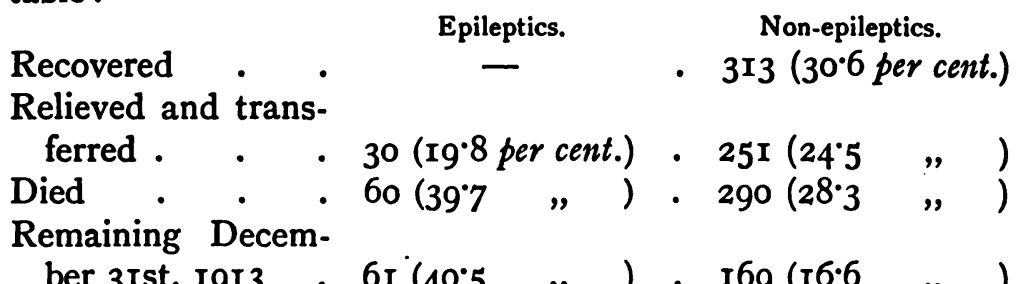

Epileptic insanity being practically hopeless, interest here attaches to the deaths, which, it will be noticed, are relatively considerably more amongst epileptics. In order to throw some light on this, I have made an analysis of roo deaths amongst epileptics, taken seriatim, and correlate certain causes with a similar analysis of the 290 non-epileptic deaths, in the following table :

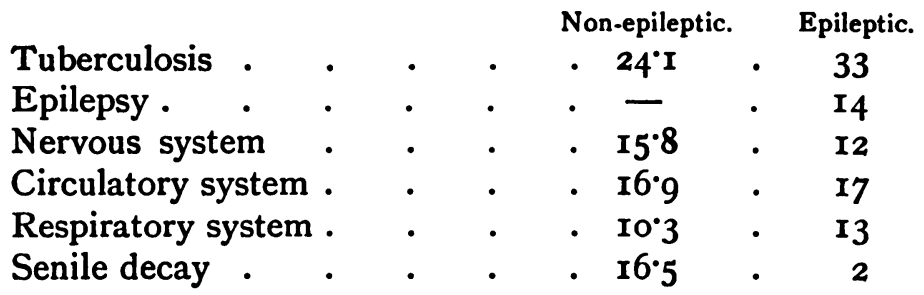

In this connection it is worthy of note how few cases of cancer one meets with amongst the insane here. Of the roo epileptic deaths only two were due to cancer, and four amongst the 290 non-epileptic. It is very questionable whether one of those listed as senile under the epileptic heading should be incorporated, as her first fit occurred after seventy years of age, and it was probably apoplectiform, though it left no paralytic after-effects and was in the nature of epilepsy, as were succeeding seizures. It will be seen that the mortality from tuber- 
culosis is nearly ro per cent. greater among epileptics, and it occurs to one's mind that this tendency to tuberculosis might be universal in this affection, and not due to infection contracted here. To help in deciding this I have divided the deaths due to tuberculosis during the ten years under consideration into four periods of two and a half years each, and the following table shows the percentage of deaths amongst those admitted in each period to the total admissions in that period up to the present time:

\begin{tabular}{|c|c|c|c|c|}
\hline & $\begin{array}{c}\text { First } \\
\text { period. }\end{array}$ & $\begin{array}{l}\text { Second } \\
\text { period. }\end{array}$ & $\begin{array}{l}\text { Third } \\
\text { period. }\end{array}$ & $\begin{array}{l}\text { Fourth } \\
\text { period. }\end{array}$ \\
\hline & $\begin{array}{l}30.2 \\
\text {. } \quad 28.5\end{array}$ & $\begin{array}{l}24^{\circ} .1 \\
25^{\circ} 0\end{array}$ & $\begin{array}{r}20^{\circ} 3 \\
\cdot \quad 13^{\circ} 2\end{array}$ & \\
\hline
\end{tabular}

It is apparent that there is a gradual increase in tuberculosis mortality, depending on duration of residence amongst the non-epileptics, which does not obtain with epileptics. Epileptics then may possibly be potent agents in raising the tuberculosis mortality of communities amongst whom they live, and the following statistics taken from the Commissioners' Report help to bear this out. Taking the dozen asylums with the highest and lowest epileptic averages, we find that the first-mentioned group has an average epileptic percentage of 18.2 and a corresponding tuberculosis mortality of $17 \cdot 8$, while the dozen having the lowest epileptic percentages show an average epileptic rate of 7.9 and a correspondingly low mortality from tuberculosis, viz., $13 \%$.

Conversely, taking the dozen asylums showing the highest tuberculosis death-rate, we find this averages at $22^{\circ} 9$ and the corresponding epileptic average is 14 ; again, those with the lowest tuberculosis mortality show an average of $10^{\circ} I$, and the corresponding epileptic ratio is $1^{\circ} 9$.

When it is recollected that, as already stated, the epileptic average in asylums for England and Wales is 12.5 and the tuberculosis mortality $16 \cdot 6$, the significance of the above figures will be apparent. Appended are the groups from which the above averages have been taken:

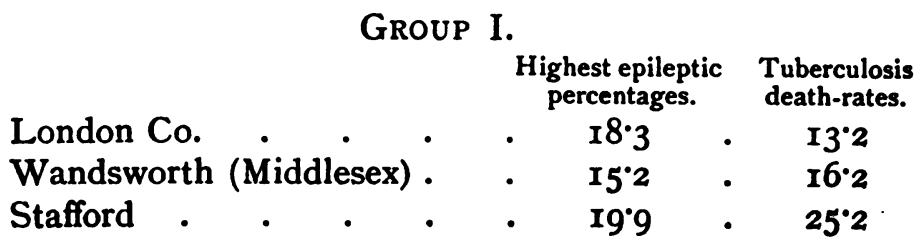




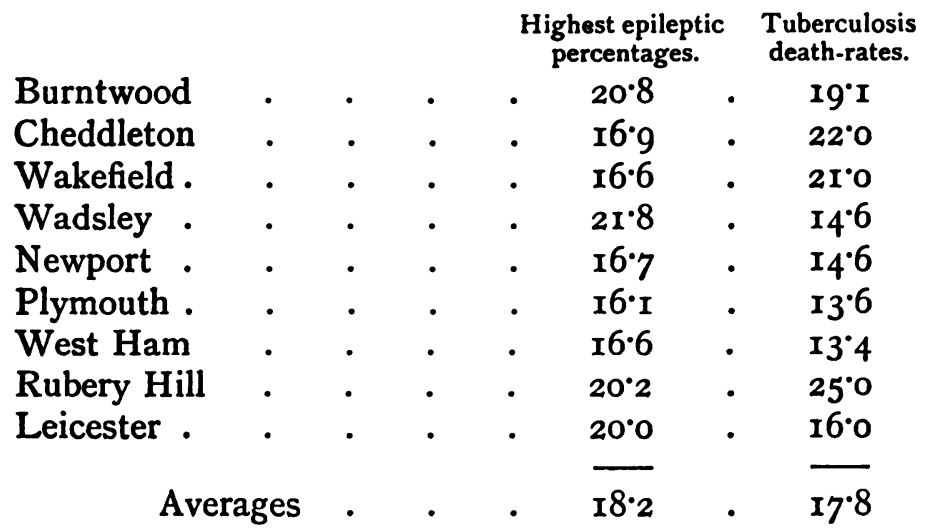

\section{GROUP II.}

\begin{tabular}{|c|c|c|c|}
\hline & & $\begin{array}{l}\text { Lowest epilept } \\
\text { Percentages. }\end{array}$ & c $\begin{array}{c}\text { Tuberculosi } \\
\text { death-rates. }\end{array}$ \\
\hline Isle of Wight. . & . & $5 \cdot 8$ & $\mathrm{II}_{4} 4$ \\
\hline Wells . & . & $6 \cdot 2$ & $12 \% 7$ \\
\hline Carmarthen & . & $7 \cdot 8$ & $23^{\circ} 2$ \\
\hline Bucks. & . & $8 \cdot 2$ & $13^{\cdot 2}$ \\
\hline Dorset & . & $8 \cdot 4$ & II $\cdot 8$ \\
\hline Brookwood & . & $8 \cdot 6$ & $I I \cdot 6$ \\
\hline Netherne. & . & $8 \cdot 7$ & $9 \cdot 5$ \\
\hline Sussex, W. & . & $8 \cdot 9$ & $17 \%$ \\
\hline Menston . & . & 6.7 & 10.9 \\
\hline Canterbury & . & $6 \cdot 9$ & $15^{\circ} 2$ \\
\hline Brecon and Radnor & . & $9^{2} 1$ & II 3 \\
\hline Cornwall . & . & 9.5 & $17 \cdot 3$ \\
\hline Averages & . & 7.9 & $13 \%$ \\
\hline
\end{tabular}

\section{GrouP III.}

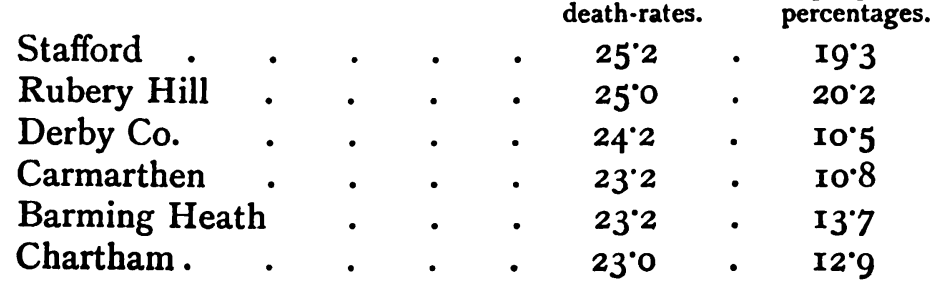




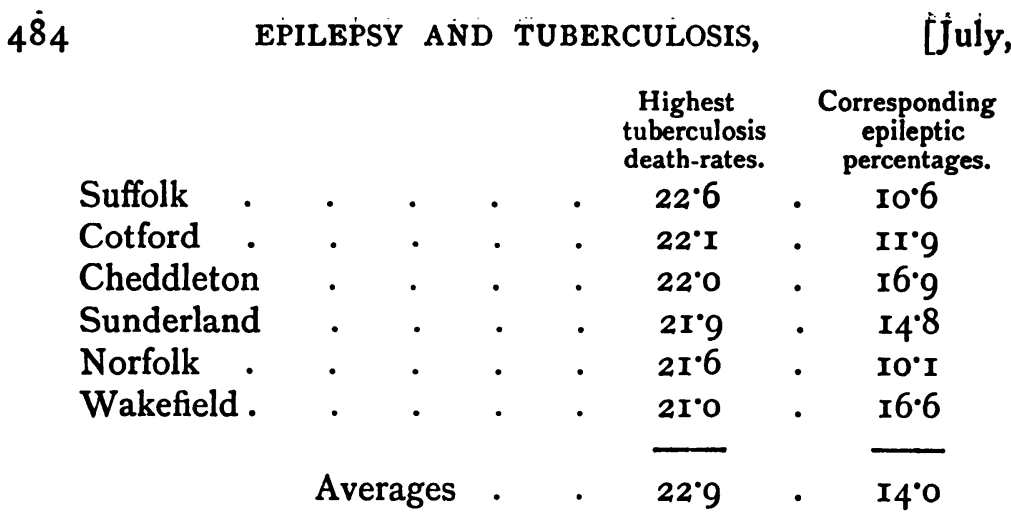

\section{Group IV.}

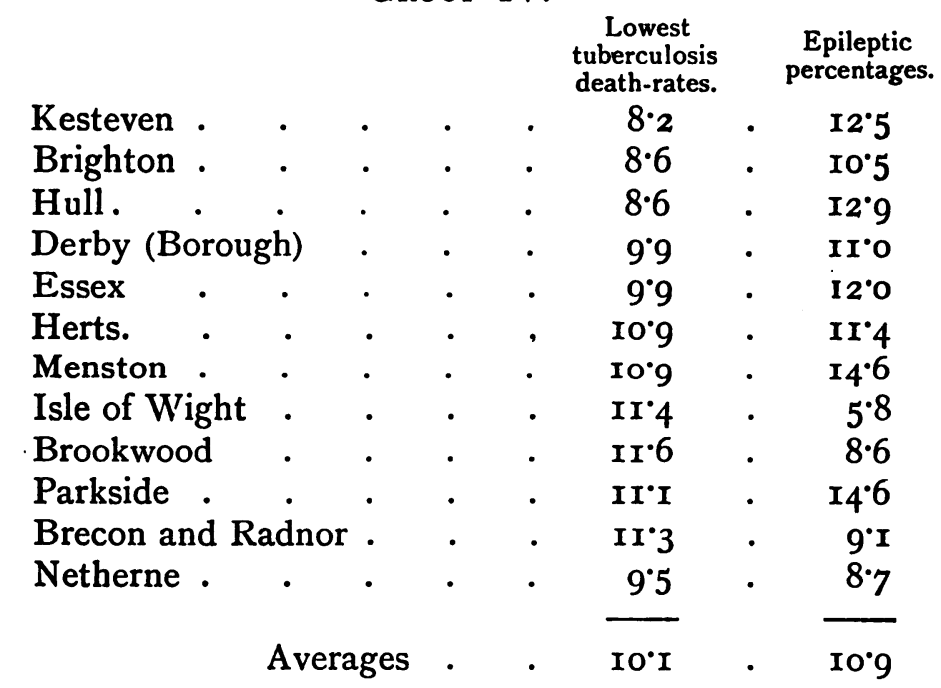

It will be noticed that Lancashire is not included, for reasons already mentioned, nor is York Borough, as the Commissioners state, referring to the proportion of epileptics there (19\%7): "We, however, learned to-day that this proportion is factitious and is due to the large number of epileptics among the cases that have been transferred here." In this connection it is also noteworthy that the Institution for the Feeble-minded at Darenth has an epileptic proportion of $18 \%$, and a death rate from phthisis of 24 per cent.

I have been in the habit for a considerable time of treating certain cases of tuberculosis here with tuberculin, and it occurred to me that it would help matters in this investigation 
to give diagnostic injections to all the patients in the epileptic ward, and at the same time to correlate the results with physical signs of pulmonary tuberculosis and alteration in weights during the past three months. I had already a series of controls amongst non-epileptics for purposes of contrast. Seventy cases from the epileptic ward were in all examined, ten of whom were non-epileptics. T. oor c.c. was the injection given, and as regards physical signs I relied principally on the alteration in the apical percussion note, and the variations in transmission of the tuning-fork note of definite intensity from the supraspinous to the infra-clavicular regions, auscultation being for the most part very unreliable in these cases owing to shallow breathing, which is very constant in all forms of insanity.

The results are given in the following series of tables:

TABLE I.

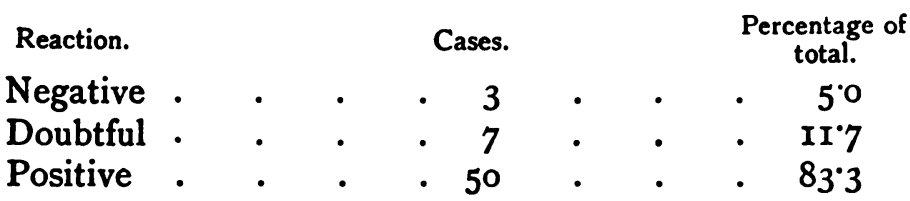

A negative reaction $I$ have considered as a rise of temperature of under $8^{\circ} \mathrm{F}$.; doubtful, $8^{\circ}$; positive, $\mathrm{I}^{\circ}$, and over.

Under the positive reactions are included two cases of initial fall of $2^{\circ}$ and $\mathrm{r}^{\circ} 4^{\circ}$ respectively; to the former I gave a course of tuberculin a year previously for definite pulmonary tuberculosis, at which time she reacted very strongly, and since when she has gained weight and is now in robust health, and employs herself very usefully; the latter showed marked right apical dulness as well.

TABLE II.-Positive Reactions arranged according to Degree of Reaction, excluding the Two Cases of Initial Fall.

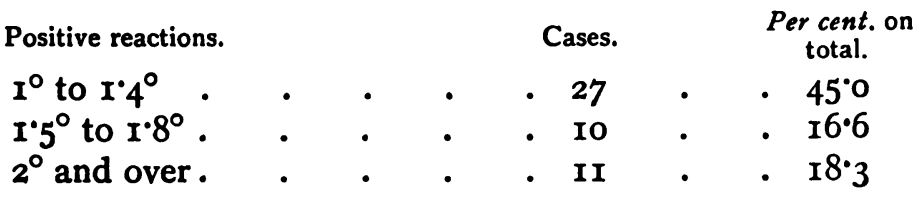


TABLE III.-Reactions correlated with Physical Signs, including the Two Cases before mentioned.

Percentage of

Physical signs. $\quad \begin{aligned} & \text { cases showing } \\ & \text { physical signs }\end{aligned}$

Reactions. Present. Doubtful. Not present. on total cases.

$\begin{array}{lrrrrrrrr}\text { Negative } & \cdot & - & \cdot & - & \cdot & 3 & \cdot & - \\ \text { Doubtful } & \cdot & \text { I } & \cdot & \text { I } & \cdot & 5 & \cdot & \mathbf{I} \cdot 6 \\ \text { Positive } & \cdot & 37 & \cdot & 6 & \cdot & 7 & \cdot & 61 \cdot 6\end{array}$

TABle IV. - Positive Reactions correlated with Physical Signs.

$\begin{array}{ccc} & \text { Physical signs. } & \begin{array}{c}\text { Percentage on } \\ \text { totals in each } \\ \text { class with } \\ \text { Reactions. }\end{array} \text { Present. Doubtful. Not present. phical signs. }\end{array}$

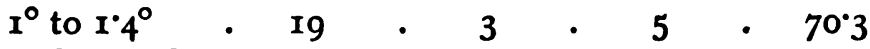

$\mathrm{I}^{\circ} 5^{\circ}$ to $18^{\circ} \cdot 7$. 2 . $\mathrm{I}$. $70^{\circ} 0$

$2^{\circ}$ and over $. \quad 9 \quad . \quad$ I $\quad . \quad$ I $\quad .81 \cdot 8$

Initial fall $\quad 2$

TABLE V.-Reactions correlated with Alteration in Weight in past three months.

\begin{tabular}{|c|c|c|c|c|c|}
\hline & & $\begin{array}{c}\text { Lost } \\
\text { weight. }\end{array}$ & Gained. & No change. & $\begin{array}{l}\text { Cases which } \\
\text { lost weight, } \\
\text { per cent. of } \\
\text { each class. }\end{array}$ \\
\hline Negative & - & - & 2 & I & - \\
\hline Doubtful & - & 2 & I & 4 & $28 \cdot 5$ \\
\hline Positive & & 20 & I7 & 13 & $40^{\circ} 0$ \\
\hline $\begin{array}{l}\text { Totals } \\
\text { Per cent. }\end{array}$ & • & $\begin{array}{l}22 \\
36 \cdot 06\end{array}$ & $\begin{array}{ll}\text {. } & 20 \\
\text {. } & 33^{\circ} 3\end{array}$ & $\begin{array}{ll}\cdot & 18 \\
. & 30^{\circ} 0\end{array}$ & \\
\hline
\end{tabular}

TABLE VI.-Positive Reactions correlated with Alteration in Weight in past three months.

\begin{tabular}{|c|c|c|c|c|}
\hline & $\begin{array}{c}\text { Lost } \\
\text { weight. }\end{array}$ & Gained. & No change. & $\begin{array}{l}\text { Cases which } \\
\text { lost weight, } \\
\text { per cent. of } \\
\text { each class. }\end{array}$ \\
\hline to & II & II & 5 & 40.7 \\
\hline & I & 4 & 5 & $10 \circ 0$ \\
\hline & 7 & 2 & 2 & $63 \cdot 6$ \\
\hline
\end{tabular}


TABLE VII.-Reactions correlated with Change in Weight in Pounds.

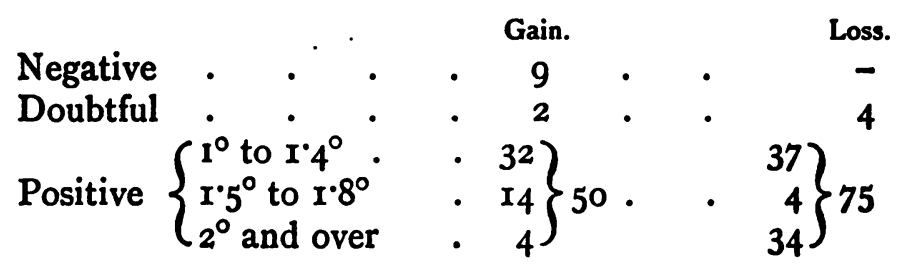

A very noticeable peculiarity amongst epileptics is the marked depression of temperature after even a comparatively small initial rise, and the quick response to the tuberculin in the first place. In 7 cases the temperature dropped to $96^{\circ}$ and below-I reaching $95^{\circ} 4^{\circ}$; in 4 cases to $962^{\circ}$, and in 6 to $964^{\circ}$; in 15 cases it dropped to between $96.8^{\circ}$ and $97^{\circ} 2^{\circ}$, so that in 31 cases, or over 50 per cent., this sudden depression was marked. In all these cases the epileptic seizures were very severe and frequent, and in the 7 cases in which the temperature fell to $96^{\circ}$, and below, exceptionally so. The thought suggests itself that this peculiarity bears some relation to nervous instability. I have been very much struck by it in epileptics as compared with others.

The frequency of subnormal temperatures amongst epileptics is very marked. Out of the 60 cases under consideration this condition was present in 35, amongst whom physical signs were present in 22, doubtfully so in 6, apparently absent in 7 cases.

With reference to Table III. The number of cases in which the right apex showed decided signs of phthisis as compared with the left is remarkable-out of the total number showing signs of tubercular deposit, viz., 38, in 33 the right apex was involved. This is a fact of very great interest when it is recollected that it is mainly on the right side that the tracheobronchial glands are implicated in children. Of these 38 cases showing physical signs, I7 lost weight.

Enumerated among the epileptics are 5 who developed epilepsy after admission here, and past middle age; 4 of these have undoubted signs of pulmonary tuberculosis, and the fifth had a reaction of over $1^{\circ} 5^{\circ}$ and had suspicious signs at one apex.

Of the ro non-epileptic patients resident in the epileptic ward the following table shows the results obtained: 


\begin{tabular}{|c|c|c|c|c|c|c|}
\hline \multirow{2}{*}{ Reactions. } & \multirow{2}{*}{ Cases. } & \multicolumn{2}{|c|}{$\begin{array}{c}\text { Pulmonary physical } \\
\text { signs. }\end{array}$} & \multicolumn{3}{|c|}{ Alteration in weight. } \\
\hline & & Present. & Absent. & Gained. & Lost. & Unchanged. \\
\hline $\begin{array}{l}\text { Negative } \\
\text { Positive : } \\
1 \cdot 5^{\circ}-1 \cdot 8^{\circ} \\
2^{\circ} \text { and over }\end{array}$ & $\begin{array}{l}2 \\
2\end{array}$ & $\begin{array}{l}2 \\
\mathbf{I}\end{array}$ & $\begin{array}{l}5 \\
-\end{array}$ & $\begin{array}{l}3 \\
-\end{array}$ & $\begin{array}{l}2 \\
2 \\
1\end{array}$ & $\begin{array}{l}1 \\
-\end{array}$ \\
\hline
\end{tabular}

It is necessary to mention that one case giving a negative reaction, viz., $4^{\circ}$ followed by a decided fall, had been treated here twelve months ago for active phthisis with hæmoptysis. She still has right apical dulness, and has lost $4 \mathrm{lb}$. in the past three months, but shows no signs of active disease. Also one case gave a positive reaction of over $2^{\circ}$. She is a recent admission, of middle age, with a markedly subnormal temperature, and is said to have suffered from epilepsy in early childhood, but has had no fits since. She has lost I lb. in the past three months, but showed no physical signs of pulmonary trouble. One case-an imbecile-gave a reaction of over $2^{\circ}$. She had marked right apical mischief, although she had gained $5 \mathrm{lb}$. in the past three months.

Leaving out the case showing a negative (?) reaction which had been treated for active phthisis previously, 50 per cent. of the non-epileptics show no indication of tuberculosis. Reviewing my previous diagnostic tuberculin work among non-epileptic patients here, I find that $33^{\circ} 3$ per cent. showed similar positive results. Considering the results from the above investigation, also the facts ascertained from the Commissioners' Report, together with the high mortality of epileptics from tuberculosis, it will at once be evident that there is a close relationship between tuberculosis and epilepsy. It has up to the present time been considered that epilepsy, by lowering vitality, predisposes to tuberculosis. No doubt, in many instances, that is so, but I suggest that the great majority of cases of idiopathic epilepsy met with in asylums-in which, as will be readily understood, the epileptic condition is very severe in degree, and has begun at a very early age-are directly due to the toxæmia resulting from invasion of the child's system by the tubercle bacillus, and its effects on a developing and naturally unstable nervous organisation, or it may be to reflex 
irritation from diseased bronchial glands. Tuberculosis rarely affects children similarly to adults; the lesion is mainly in the tracheo-bronchial glands. I have been from time to time struck at post-mortem examinations on epileptics by the size of these glands, especially those on the right side. Recently I made a post-mortem examination on an epileptic who had given a positive reaction to a diagnostic tuberculin injection, but who had had no physical signs pointing to pulmonary tuberculosis. She died later showing all the signs of rapid tuberculosis, and the necropsy disclosed suppurating and caseous bronchial glands, and invasion of adjacent bronchi, but the lung-tissue itself showed no tuberculous deposit. In Vienna it has been shown that 90 per cent. of the school-children under the age of ten or eleven have been infected with tubercle. "Hamburger, of Vienna, among eighty-six cases of localised tuberculosis, found the primary lesion in the bronchial glands in eighty-five," Still in 8I per cent., and Carr in 80 per cent. (Early Diagnosis of Tubercle, Riviere.)

We know that in incipient tuberculosis muscular exercise will bring about an auto-inoculation reactive rise of temperature, due to the flushing of toxins from the tubercular focus into the blood, and that this fact is taken advantage of for treatment; bearing it in mind $I$ have had the temperatures of a number of epileptics taken, and am now constantly having this done for diagnostic purposes, immediately after a fit, and two-hourly for ten or twelve hours. I find that the results roughly correspond, but to a lesser degree, to the effects of the diagnostic tuberculin injection; in a few cases a surprising rise of temperature has occurred, and in some a fall, to be explained probably by the degree of toxæmia present. Tuberculosis is undoubtedly very rife amongst children in the poorest parts of thickly populated areas, as compared with the rural districts, and it is apparent that the children in these industrial districts cannot get the same care and attention from mothers who have often occupations to attend to other than domestic. The percentage of occupied to unoccupied married women is, for urban districts -England and Wales-12.9, and for rural 6*2. Now when a child whose vitality is lowered through lack of care and proper nourishment, to say nothing of fresh air, and who may in addition suffer from unstable nervous heredity, contracts tuberculosis, it may be quite conceivable either that a reflex effect is 
induced, or that the toxins thrown into its system from the tubercular focus have an action, centric or synaptic, on the child's partially developed and ill-regulated nervous organisation, resulting in disturbance of the normal balance, andespecially in cases predisposed thereto by inherited nervous instability - the immediate result is an epileptic seizure, which, by bringing about auto-inoculation, has the effect of rendering

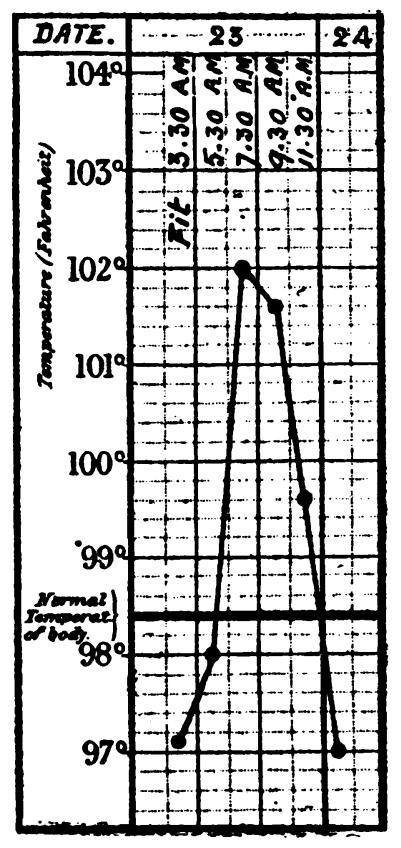

Снart 1.-Reaction after fit in case of epilepsy showing no signs or symptoms of pulmonary tuberculosis.

the toxic focus somewhat quiescent for a time. When the effects of this auto-tuberculinisation wears off the fit recurs, and after a time the sensitive neurones acquire a habit, or synaptic changes take place, from which recovery becomes unlikely. This constant auto-inoculation, after a longer or shorter time, either brings about cure of the tuberculous lesion, the danger of recurrence of the epileptic seizures being in direct ratio to the length of such period, or it keeps the toxin-producing focus in check, until debility from exhaustion of one kind or another deteriorates the defensive powers of the system, and rapid 
tuberculosis results. It will be familiar to everyone having experience of epileptics what a low asthenic form the tuberculous process takes in them, and how advanced the lesions are bost-mortent.

The percentage of epileptics in the urban and rural districts here under notice is respectively 24 and $13^{\circ} 5$, and the RegistrarGeneral's Report shows in urban districts a similar preponder-

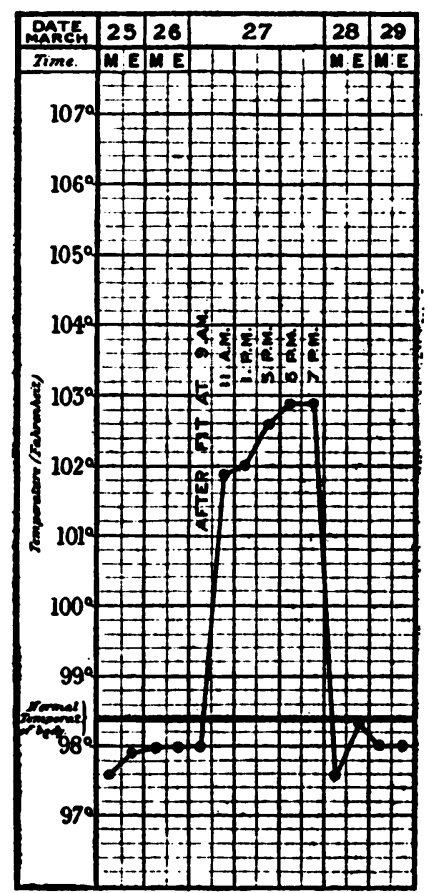

Chart 2.-Case of definite pulmonary tuberculosis in an epileptic showing marked reactive rise in temperature after a fit, previous to which and afterwards her temperature was subnormal.

ance of infantile mortality from tuberculosis, convulsions and atrophy, debility and marasmus.

$$
\begin{aligned}
& \begin{array}{c}
\text { County } \\
\text { boroughs. Rural districts. }
\end{array} \\
& \text { Tubercular meningitis } \quad \text {. } \quad \text {. } \quad \mathbf{I} 28 \quad \text { • } \quad 89 \\
& \text { Pulmonary tuberculosis } \quad . \quad \text {. } \quad 50 \quad \text {. } 50 \\
& \text { Atrophy, debility, and marasmus } 17 \cdot 41 \quad \text {. } 14^{\circ} 84
\end{aligned}
$$$$
\text { Abdominal tuberculosis . . } \quad \text { r79 } \quad \text {. r.r4 }
$$$$
\text { Convulsions . . . . } 1 \mathrm{Ir}^{\circ} 5 \mathrm{O} \quad 9^{\circ} 42
$$$$
\text { Just as, at a very early age, the toxæmia resulting from }
$$ 
rickets will cause convulsions, laryngismus stridulus, and carpopedal spasms, so, somewhat later, epilepsy may become established, as I have endeavoured to describe, by the toxæmia of tuberculosis. If this is the case, it is important that all cases of early epilepsy should be tested with tuberculin, and the state of their bronchial glands thoroughly investigated by means of the Röntgen rays. At that early age, if taken in time, a course of tuberculin treatment might cure the epilepsy. I have given such a course to one epileptic without apparently having any ameliorating effect on the seizures, but this result could scarcely be expected once the nervous system had firmly acquired the epileptic habit.

To recapitulate briefly, I have shown :

(I) That it is to the industrial districts we owe our high epileptic ratio in this Institution, and that urbanisation appears to principally affect the females in this direction in our neighbourhood.

(2) That the high death-rate amongst male children in Wolverhampton relatively to female is probably associated with the great excess of female epileptics there.

(3) That a high epileptic ratio is constantly associated with a high tuberculosis incidence, and vice versâ.

(4) That the death-rate from tuberculosis amongst the nonepileptic is directly proportional to length of residence, which does not obtain amongst the epileptic.

(5) That the number of positive, and suspiciously positive, reactions to tuberculin amongst epileptics here is 95 per cent.

(6) That only 50 per cent. of non-epileptic patients associated intimately with the epileptics show a similar reaction.

(7) That, associated with a high ratio of epileptics in urban relatively to rural districts, is a similarly high infantile and early childhood mortality from tuberculosis, convulsions, and atrophy, debility and marasmus, and also a correspondingly high proportion of occupied married women, which it would be well for employers of female labour to bear in mind.

(8) That, except in terminal cases of active tuberculosis, loss of weight is not a valuable criterion of the presence of tuberculosis in epileptics.

(9) It is contended that epilepsy may be an evidence of tubercular infection in childhood, probably affecting the bronchial glands initially, and that the convulsions are due either to reflex 
irritation so set up, or to the resulting toxæmia acting on an unstable nervous system, either inherited or acquired. Further, that the constantly recurring seizures not only establish a vicious habit as far as the nervous system is concerned, but also effect tuberculin auto-inoculation, thus tending to keep the tuberculous process in check, so that, instead of a fatal termination, epilepsy results.

(Io) Consequently, the advisability of carefully searching for - tubercular foci in children the moment epileptic fits develop, and also the immediate use of tuberculin in their treatment, should receive consideration.

\section{Clinical Notes and Cases.}

\section{$A$ Case of Hereditary Deaf-mutism with Pedigree. By}

O. P. NAPIER PEARN, M.R.C.S.(Eng.), L.R.C.P.(Lond.), Assistant Medical Officer, Horton Asylum, Epsom.

INQUIRIES into the family histories of the pauper insane in large urban districts as a rule result in the acquisition of more disappointment than knowledge.

The patients are drawn from the flotsam and jetsam of a great city, in which residence at one address for a long period is the exception rather than the rule, and their relatives are often unable to give any information except as to their immediate collaterals and predecessors. Personal interviews with fathers and mothers frequently do little beyond establishing an element of immediate parental heredity in the patient's mental anomalies, and to ignorance is sometimes added a prejudiced reticence.

The pedigree of the case described below therefore acquires additional interest by virtue of its rarity. The patient in question is a moral imbecile whose personal history is as follows :

P. S-, first manifested overt mental abnormalities at the age of four, when he was subject to outbreaks of uncontrollable passion. He was sent to a special school where he developed a habit of petty pilfering, was careless of the calls of nature, indulged in masturbation, and exhibited himself rude in the girls' dormitory, being finally expelled at the aged of fifteen. He next spent some time with various relations, but was so intolerant of restraint that he was placed in a home for the deaf and 